\section{ФИЛОСОФИЯ}

Конечно, в художественном фильме присутствует и реконструкция событий. Но если реконструкция в документальном кино имеет лишь гипотетический характер, художественные сцены в нем лишь предположение и условность, в то время как в кино, снятом по реальным событиям, реконструкции и гипотез нет и не может быть, всё подлинно, а потому реконструкция есть всегда иллюстрация чьей-то истории. Будь то история, рассказанная очевидцем, участником или современником этих событий.

Итак, кино, основанное на реальных событиях, есть осуществленное в художественной форме высказывание об историческом событии, которое по форме старается скрыть свое субъективное происхождение благодаря натурализации культурного, т. е. возведению культурного из исторического пространства в пространство метафизическое и десубъективации, по содержанию же стремится к тому, чтобы утвердить свою объективную значимость для общества благодаря освоению природного и исторического пространства за счет расширения границ современной культуры.

1. Genius Begins at Home: Shared Social Identity Enhances the Recognition of Creative Performance / N. K. Steffens, A. S. Haslam, M. K. Ryan, K. Millard // British Journal of Psychology. 2017. Vol. 108, Is. 4. P. 721-736.

УДК 128

Науч. спец. 09.00.13

DOI: 10.36809/2309-9380-2020-29-16-20

\section{O ТРАНСГУМАНИЗМЕ КАК МИРОВОЗЗРЕНИИ}

В статье приводится анализ предлагаемой в трансгуманизме идеи необходимости использования передовых научно-технических достижений в целях совершенствования биологической природы человека и преодоления таким образом нависших над человечеством глобальных проблем и угроз. Делается вывод о недостаточной обоснованности оптимистичных прогнозов трансгуманистов в отношении достижения состояния бессмертия, поскольку возможность применения современных технологий в целях «усовершенствования» человека сталкивается и порождает сложнейшие технические и этические проблемы. В дополнение этой критике предлагается критическое рассмотрение мировоззренческого аспекта относительно возможных последствий подобного технологического изменения человеческой природы.

Ключевые слова: трансгуманизм, бессмертие, смерть, биотехнологии, искусственный интеллект.
2. Денисов С. Ф., Денисова Л. В. Систематика околонаучного знания // Ом. науч. вестн. 2013. № 5 (122). С. 81-85.

3. Лотман Ю. М. Символ в системе культуры // Лотман Ю. М. Избранные статьи : в 3 т. Т 1: Статьи по семиотике и топологии культуры. Таллин : Александра, 1992. С. 191-199.

4. Про А. Двенадцать уроков по истории. М. : Рос. гос. гуманитар. ун-т, 2000. 336 с.

5. Аверинцев С. С. София-Логос. Словарь. 2-е изд. Киев : Дух и Литера, 2001. С. 155-161.

6. Гегель Г. В. Ф. Лекции по эстетике : в 2 т. 2-е изд. СПб. : Наука, 2007. Т. 1. 623 с.

7. Барт Р. Третий смысл. М. : Ад Маргинем Пресс, 2015. $104 \mathrm{c}$.

8. Кракауэр 3. Природа фильма. Реабилитация ффизической реальности. М. : Искусство, 1974. 442 с.

9. Сантаяна Дж. Фотография и мысленный образ // Метафизические исследования. Дагерротип. Вып. 214. СПб. : Изд-во Санкт-Петербургского философрского общества, 2010. С. 145-155.

10. Базен А. Что такое кино? М. : Искусство, 1972. 384 с.

11. Кант И. Критика эстетической способности суждения. Собр. соч. : в 6 т. М. : Мысль, 1966. Т. 5. С. 201-379.

(C) Добронравов К. О., 2020

\title{
ON TRANSHUMANISM AS A WORLDVIEW
}

The article offers an analysis of the idea proposed in transhumanism of the need to use advanced scientific and technological achievements in order to improve the biological nature of man and thus overcome the global problems and threats hanging over humanity. It is concluded that the optimistic predictions of transhumanists are insufficiently substantiated in relation to achieving the state of immortality, since the possibility of using modern technologies for human "improvement" collides with and gives rise to complex technical and ethical problems. In addition to this criticism, a critical consideration of the worldview aspect is proposed regarding the possible consequences of such a technological change in human nature.

Keywords: transhumanism, immortality, death, biotechnologies, artificial intelligence.

носят неоднозначный и противоречивый характер: с одной стороны, они сулят процветание и комфортное существование, с другой стороны, в них начинают просматриваться крайне опасные для человечества угрозы и проблемы. 
Особенно острым стоит вопрос в отношении возможности применения передовых технологий в целях изменения биологической природы самого человека. Такие перспективы «усовершенствования» человеческой природы требуют глубокого анализа его осуществления и возможно даже пересмотра многих фундаментальных ценностей. Как отмечает израильский историк Юваль Ной Харари, «будущие революции в биотехнологиях и ИТ [информационных технологиях], скорее всего, потребуют формирования нового мировоззрения» [1, с. 33].

Интересная и оригинальная попытка осмысления и возможных перспектив применения к человеку современных технологий, и роли техники в современном мире в целом предлагается в рамках концепции трансгуманизма. В трансгуманистических идеях поднимаются на повестку дня сложнейшие проблемы и делаются смелые, вызывающие острые дискуссии, предложения в отношении решения этих проблем. Поэтому их рассмотрение и анализ открывают возможность для поисков ответов: каким образом передовые технологии могут повлиять на наше существование и как избежать на этом пути роковых ошибок?

Под трансгуманизмом, вслед за одним из известных сторонников этого движения М. Мором, следует понимать философию, «которая стремится к продолжению и ускорению эволюции разумной жизни за пределами ее нынешней человеческой формы и человеческих ограничений с помощью науки и техники» [2]. Трансгуманисты Н. Бостром, Д. И. Дубровский, Д. И. Ицков, Р. Курцвейл, М. Мор, М. Тегмарк и др. в своих работах придерживаются воззрений, которые кратко можно изложить в виде следующих тезисов:

- современное человечество подходит к поворотному моменту в своей истории, когда оно может быть либо уничтожено из-за нависших над ним глобальных проблем, либо перейдет на новый уровень развития;

- в качестве инструментария, способствующего преодолению человечеством своего кризисного состояния, должны выступить передовые научно-технические достижения в области биотехнологий и нанотехнологий, робототехники, исследовательских разработок в медицине по продлению человеческой жизни, исследований активности мозга в нейронауках, в проектах по обратному проектированию мозга, созданию искусственного интеллекта и информационных технологий в целом и т. д.;

- огромный потенциал перечисленных выше технологий должен быть применен для исправления главной причины всех бед человечества - несовершенной человеческой природы;

- в случае успешного применения к людям данных технологий в целях их усовершенствования человек должен быть преобразован в нео- или постчеловека;

- по сравнению с нынешним человеческим существованием возможный переход на стадию постчеловеческого существования следует оценивать как более совершенный этап эволюционного развития жизни, который предоставит людям возможность развиваться как в физическом и духовном, так и в пространственно-временном (продление продолжительности жизни вплоть до состояния, близкого к бессмертию, и расширение границ обитания посредством освоения космоса) аспектах.
Таким образом, трансгуманисты считают, что при помощи научно-технического потенциала современной цивилизации можно не только преодолеть нависшие над ней угрозы, но и взять под целенаправленный контроль естественные эволюционные процессы и затем направить их в желательное для человечества русло. Например, Д. И. Ицков подобную целевую установку трансгуманистического учения выражает следующими словами: «Мы выдвигаем стратегию духовного и научно-технологического прорыва, эволюционного трансгуманизма, на основе которой человечество сможет перейти к сознательно управляемой эволюции впервые в своей истории» [3, с. 8].

Важно отметить, что трансгуманисты, предлагая свою концепцию в качестве варианта решения угрожающих существованию человечества проблем, последовательно пытаются разрешить с позиции технологического детерминизма и многие мировоззренческие вопросы. Ими, в частности, поднимаются такие проблемы мировоззренческого характера, как: проблема постижения человеческой сущности, вопросы о саморазвитии и определении смысла жизни, об отношении человека к своей смертной природе и т. д.

Главный связующий компонент в мировоззрении трансгуманистов, на основе которого выстраивается их позиция в отношении решения всех интересующих их мировоззренческих проблем, - вопрос о преодолении смерти и возможности достижения состояния бессмертия. Как отмечает И. В. Дёмин, в форме трансгуманизма проявляется «...мировоззрение, которое усматривает главную (конечную) цель человеческих устремлений в преодолении природной обусловленности человека, символом и квинтэссенцией которой выступает смерть...» [4, с. 7]. Поэтому трансгуманисты интегральную цель своих исканий видят в необходимости преобразования человека в постчеловека ради обретения кибернетического бессмертия.

Феномен человеческой смерти в рамках трансгуманизма получает исключительно негативную оценку, она предстает в качестве антиценности, не имеющей никакого положительного или содержательного смысла и носящей сугубо деструктивный характер. Такую мировоззренческую установку трансгуманист Р. Курцвейл выразил следующим образом: «"Смерть придает жизни смысл" - гласит древняя поговорка, но, на наш взгляд, смерть делает прямо противоположное. Она ворует... вещи, которые делают жизнь достойной того, чтобы жить... сама жизнь - и всё, что мы можем сделать в ней, - придает бытию смысл» [5, с. 349]. Для трансгуманистов смерть лишается своей таинственности и хоть какой-то метафизической значимости. Например, Д. И. Дубровский данное обстоятельство выразил следующим образом: «Если для биологической эволюции и биологических форм существования смерть действительно имеет глубокий смысл, служит непременным фактором развития жизни, то для кибернетической эволюции она теряет всякое значение» [6, с. 196]. Смертная природа человека в трансгуманизме предстает как нежелательная помеха, препятствие или, как метко подметил Ю. Харари, «проблема техническая, которая может и должна быть решена» [7, с. 31]. Поэтому трансгуманисты мечтают об изменении смертной 
природы человека, представляющей собой главное препятствие для возможности насладиться жизнью и полностью реализовать свой творческий потенциал. Ключ к решению этой проблемы, по их мнению, заключается в огромных возможностях современных технологий, гипотетически способных инструментально устранить недостатки человеческой природы. С точки зрения сторонников трансгуманизма, благодаря этим передовым технологиям возможно и преобразование человека в практически бессмертного постчеловека, который преодолеет недостатки человеческой природы, будет иметь все возможности для почти безграничного саморазвития и будет способен решить все волнующие его вопросы. Такие трансгуманистические надежды на технику М. Тегмарк отметил в следующих словах: «Нет нужды ограничивать наши устремления и мечты отрезком в сотню лет, отведенных для жизни среди болезней, нищеты и невежества. Напротив, благодаря развитию технологий жизнь получает возможность процветать миллиарды лет, и не только здесь, в Солнечной системе, но и по всему космосу» [8, с. 312].

Возникает естественный вопрос: насколько осуществимы в реальности фантастические предположения, которые выдвигаются трансгуманистами?

Предлагаемые сторонниками трансгуманизма идеи у многих исследователей вызывают скептическую и критическую оценки. Из множества критических работ по этой проблематике особенно известны книги Ф. Фукуямы [9] и Ю. Хабермаса [10], которые показали, что возможное применение современных технологий в целях усовершенствования человеческой природы:

- изначально скомпрометировано своей схожестью с заложенными в евгенике целями и вызывает острые дискуссии по потенциальному возвращению в рамках таких исследований к расистским доктринам;

- может породить огромное количество этических проблем;

- может привести к обострению социально-политических проблем, а также социального неравенства в форме биологического неравенства как нового вида разделения людей по социальному статусу;

- может стать крайне опасным экспериментом, поскольку знания людей в этой области незначительны и последствия подобных исследований носят непредсказуемый характер.

По моему мнению, к рассмотрению подобных технических и этических проблем в отношении применения современных технологий в целях «усовершенствования» человека следует добавить критическое осмысление мировоззренческого аспекта относительно возможных последствий такого воздействия на человеческую сущность. Для этого необходимо ответить, как минимум, на два взаимосвязанных вопроса.

Первый вопрос стоит поставить следующим образом: насколько оправданы надежды трансгуманистов на развитие техники и технологий как основного средства и условия для поиска решений на волнующие его мировоззренческие вопросы и проблемы? На этот вопрос можно дать частичный положительный ответ: знание по одним миро- воззренческим вопросам актуализируется и расширяется, а по другим - вряд ли. Трансгуманисты абсолютно правы в том, что развитие технологий может способствовать активному обсуждению связанных с самопознанием вопросов, с нашими попытками постичь свою сущность, побуждать к пересмотру сложившихся представлений по многим аспектам человеческого существования. Например, для Р. Курцвейла изучение возможностей создания искусственного интеллекта способствует самопознанию человека и расширению представлений о собственной сущности. Исследования по этой проблеме, по его мнению, заставляют к постижению механизмов работы одного из самых малоизученных человеческих органов - мозга. Подобная установка заниматься осмыслением вопроса сущности человеческой природы неоднократно проскальзывает в публичных выступлениях и работах Курцвейла. Например, в одной из своих книг он пишет, что «у проекта по обратному проектированию мозга есть и еще одна важная цель - помочь нам понять, кто мы такие» [11, с. 303]. Следовательно, осмысление возможностей создания искусственного интеллекта приводит к тому, что наши устоявшиеся представления о сущности человеческого естества пересматриваются и появляется новое знание в отношении этой мировоззренческой проблемы.

Однако, стоит скептически отнестись к убежденности трансгуманистов в том, что современные технологии могут создать условия для достижения самой главной для них цели - победы над смертью и бессмертия ради продолжения бесконечно длинной и наполненной смыслом жизни. Та перспектива развития технологий, которую в своих книгах прогнозируют для человечества трансгуманисты, на самом деле не столь оптимистична и безоблачна. Она, как было отмечено выше, сталкивается с крайне сложными техническими проблемами, которые вряд ли можно будет разрешить в ближайшие десятилетия. Более того, совершенствование технологий и создание превосходящего возможности человеческого разума искусственного интеллекта не только несет благо, но и таит в себе огромное количество угроз человечеству, вплоть до его уничтожения. Как пишет сторонник трансгуманизма М. Тегмарк, «развитие технологий дает жизни небывалые возможности, она может либо процветать, как никогда ранее, либо уничтожить себя» $[8$, c. 60].

Исходя из неоднозначности перспектив преодоления смертной природы человека и необходимости критики мировоззренческих идей трансгуманизма, стоит задаться вторым вопросом: действительно ли смерть - абсолютное зло, а возможность достижения состояния, близкого к бессмертию, несет только благо?

Глупо спорить с тем, что кончина любого человека трагическое и печальное событие, при котором смерть выступает разрушительной и неумолимой силой, отнимающей жизнь. Нельзя и отрицать того, что осознание своей смертности может вызвать в человеке сильный страх, апатию, чувство абсурдности всего происходящего и прочие негативные эмоции. Поэтому совершенно закономерными и естественными выглядят желание большинства людей прожить как можно дольше и приложение ими всевозмож- 
ных «усилий, направленных на продление земной жизни» [12, с. 153].

Однако в то же время стоит согласиться с позицией известного российского гуманиста В. А. Кувакина, относящего смерть к числу основных жизненных ценностей. «Каким бы странным это ни казалось, но смерть выполняет особенно важные ценностные функции и сама она в этом измерении становится ценностью» [13, с. 194]. Смерть, находясь в диалектическом единстве с жизнью, оказывает огромное положительное воздействие на человеческое существование.

В первую очередь смертная несовершенная природа человека побуждает его дорожить своей жизнью, ценить и радоваться тем мгновениям, которые могут больше не повториться. «Обрамляя своей ослепляющей темнотой пространство жизни, смерть, как кажется, невольно, не желая того, придает ей особую ценность, яркость, особенную уникальность и прелесть; жизнь становится для нас особенно дорогой и близкой, заслуживающей уважения и высокой оценки...» [13, с. 194] - ёмко подчеркнул данное обстоятельство В. А. Кувакин.

Другая важная роль смерти заключается в том, что она порождает в человеке желание хоть как-то отложить или преодолеть неизбежность своего конца и приобщиться к чему-то вечному. Как отмечает И. В. Дёмин, «уже само полагание смерти как чего-то неизбежного выдает в человеке подспудное несогласие с ней» [4, с. 10]. Такая человеческая способность к трансцендированию особенно ярко проявляется в религии и в творчестве. Как ни парадоксально звучит, но сами трансгуманисты, нацеленные в своей изобретательской и исследовательской деятельности на преодоление смертной природы человека, во многом мотивируются собственным страхом перед смертью и желанием отложить момент собственной кончины.

Еще стоит отметить, что осознание факта неизбежности своей кончины подталкивает людей к обдумыванию смысла своего существования. Т.В.Черкозьянова, изучая роль смерти в качестве фрактора, пробуждающего интерес к осмыслению жизненных целей, писала следующее: «Именно деструктивная сила смерти, положенная в основание культурогенеза, является принципом управления в процессе смыслообразования» [14, с. 4].

Также важно подчеркнуть, что связанные с близостью смерти ситуации побуждают проявлять людей свои нравственные качества. С одной стороны, перед лицом смертельной угрозы человек часто показывает себя не с лучшей стороны, совершая трусливые действия, подлость или предательство. Но, с другой стороны, люди, противостоя смерти или даже принимая ее с покорностью, являют достойные восхищения примеры героизма, жертвенности, отваги, смирения, сострадания и т. д.

Таким образом, получается, что, хотя смерть противоположна жизни, человеческая рефрлексия вокруг своей конечности несет в себе жизнеутверждающее и исполненное смыслом начало. Ф. Фукуяма писал: «Человеку, который не сталкивался со страданием или смертью, не хватает глубины» [9, с. 246]. Без наличия в человеческом существовании неизбежной смерти существенно изменится содержание и смысл свободы, любви, творчества и т. д. А эти ценности «являются системообразующим фактором всей жизни человека, способным превратить ее в драму или привнести в нее гармонию и счастье» [15, с. 111]. В связи с этим мировоззренческую позицию трансгуманистов в отношении смертной природы человека стоит считать крайне упрощенной, а возможные для человечества последствия ее преодоления - неоднозначными и не способными принести только одно благо.

Критическое восприятие отношения трансгуманистов к феномену смерти усиливается осуществляемой ими переоценкой значимости человеческого тела. Например, Р. Курвейл по причине того, что тело человека способно сохранять свое здоровье лишь до 25 лет, а затем начинает «страдать от разрушительного воздействия процесса, известного как старение» [5, с. 25], предлагает, что его стоит считать несовершенным и что им можно «пожертвовать» путем киборгизации людей ради их бессмертия.

Однако человек - целостное телесно-духовное существо. Его плоть представляет собой значимый компонент, во многом определяющий содержание человеческой сущности. Как писал П. А. Флоренский, человек «прежде всего и первее всего... дан телесно, — как тело» [16, с. 223]. Человеческая плоть, несмотря на определенные ее недостатки, наделена многими возможностями и обладает огромным потенциалом для дальнейшего развития, пластично и не лишено эстетической ценности. Тело значимо для индивида, и каждый «стремится к максимальному самосохранению, выражаемому в стремлении любой ценой как можно более долго поддерживать свою представленность в качестве тела» [17, с. 110]. Утрата человеческого тела в качестве своеобразной «платы» за достижение состояния бессмертия не обязательно ведет к лучшей форме существования. По мнению С. Хольма, высока вероятность того, что бессмертные постлюди «окажутся не улучшенной, а ухудшенной, деградировавшей версией современного человека» [18, с. 6].

Таким образом, анализ мировоззренческих исканий трансгуманистов показал, что современная техника и технологии хотя и обладают огромным потенциалом, но в их отношении не стоит быть чрезмерно оптимистически настроенным. Вместо перспективы достижения бессмертия, которое по-прежнему остается для людей неосуществимой и опасной мечтой, стоит ставить более реалистичные и взвешенные цели. В частности, можно направить усилия на поиск способов существенного продления продолжительности человеческой жизни. Следуя в этом направлении, можно одновременно и сохранить человеческую природу от сомнительных попыток усовершенствования, и продлить время существования человека, чтобы можно было прожить долгую, счастливую, содержательную и наполненную глубоким смыслом жизнь.

1. Харари Ю. Н. 21 урок для XXI века. М. : Синдбад, 2019. 416 c.

2. More M. The Philosophy of Transhumanism. URL: https:// media.johnwiley.com.au/product_data/excerpt/10/11183343/111 8334310-109.pdf (дата обращения: 09.03.2020). 
ФИЛОСОФИЯ

3. Ицков Д. И. Общественное движение «Россия 2045» и глобальное будущее // Глобальное будущее 2045: Антропологический кризис. Конвергентные технологии. Трансгуманистические проекты : материалы Первой Всерос. конфф., Белгород, 11-12 апреля 2013 г. / под ред. Д. И. Дубровского, С. М. Климовой. М. : Канон+, 2014. С. 8-14.

4. Дёмин И. В. Бессмертие как проект: смерть и бессмертие человека в контексте гуманистического и трансгуманистического типов мировоззрения // Онтология проектирования. 2013. № 4 (10). С. 7-17.

5. Курцвейл Р., Гроссман T. Transcend: девять шагов на пути к вечной жизни. М. : Манн, Иванов и Фербер, 2015. 384 c.

6. Дубровский Д. И. Природа человека, массовое сознание и глобальное будущее // Глобальное будущее 2045: Антропологический кризис. Конвергентные технологии. Трансгуманистические проекты : материалы Первой Всерос. конф., Белгород, 11-12 апреля 2013 г. / под ред. Д. И. Дубровского, С. М. Климовой. М. : Канон+, 2014. C. 188-199.

7. Харари Ю. H. Homo Deus. Краткая история будущего. М. : Синдбад, 2018. 496 с.

8. Тегмарк М. Жизнь 3.0. Быть человеком в эпоху искусственного интеллекта. М. : АCT : CORPUS, 2019. 560 с.

9. Фукуяма Ф. Наше постчеловеческое будущее: Последствия биотехнологической революции. М. : АСТ : ЛЮКС, 2004. 349 с.

УДК 7.01

Науч. спец. 09.00 .01

DOI: 10.36809/2309-9380-2020-29-20-22

\section{ПРОСТРАНСТВО МУЗЕЯ В КИТАЕ: КЛОНИРОВАНИЕ ИЛИ ПРОРЫВ В НОВОЕ ЭСТЕТИЧЕСКОЕ ПРОСТРАНСТВО?}

В статье рассматривается феномен китайского тиражирования. Предпринята попытка выявить причины и следствия такого масштабного тиражирования как одного из ведущих направлений развития современных культурных индустрий при поддержке государственной политики Китайской Народной Республики (КНР). Репродуцирование рассмотрено как начальная ступень созидательности нового пространства, где оригинальность и новизна противопоставляются полноте.

Ключевые слова: оригинальность, тиражирование, уникальное, копия, реплика, искусство Китая, музей подделок.
10. Хабермас Ю. Будущее человеческой природы / пер. с нем. М. : Весь Мир, 2002. 144 с.

11. Курцвейл Р. Эволюция разума. М. : Э, 2015. 352 с.

12. Старцева В. С. Исторические модификации трансгуманизма // Сетевой научный журнал ОрелГАУ. 2017. № 1 (8). C. $152-157$.

13. Кувакин В. А. Твой рай и ад: Человечность и бесчеловечность человека (Философия, психология и стиль мышления гуманизма). СПб. : Алетейя ; М. : Логос, 1998. 360 с.

14. Черкозьянова Т. В. Смыслообразующие функции смерти в культурогенезе : дис. ... канд. филос. наук. М., 2003. $142 \mathrm{C}$.

15. Изотов М. О. О возможности свободы в любви // Свобода совести и диктатура миросозерцания: История взаимоотношений и современные реалии : коллективная монография. Орел : Издательство Картуш, 2016. С. 111-115.

16. Флоренский П. А. Столп и утверждение истины: Опыт православной теодицеи. М. : АСТ, 2003. 640 с.

17. Бухаров Д. Н. Тело как приоритетная ценность и ее влияние на идентичность человека // Вестн. Нижегор. ун-та им. Н. И. Лобачевского. Серия: Социальные науки. 2012. № 3 (27). С. 109-115.

18. Хольм С. Философркие проблемы в оценке постчеловеческого будущего // Человек. 2016. № 4. С. 5-15.

(C) Изотов М. О., 2020

\section{MUSEUM SPACE IN CHINA: CLONING OR BREAKTHROUGH INTO A NEW AESTHETIC SPACE?}

The article examines the phenomenon of Chinese replication. An attempt is made to identify the causes and consequences of such a large-scale replication as one of the leading areas of development of modern cultural industries with the support of the state policy of the PRC. Reproduction is considered as the initial stage of creativity in a new space, where originality and novelty are opposed to completeness.

Keywords: originality, replication, unique, copy, replica, Chinese art, Museum of forgeries.

Тема подделки и репродукции произведений искусства всегда была актуальной для сферы искусства. Сейчас эта тема, ввиду всё большего распространения производства реплик, привлекает внимание специалистов разных областей: подделку можно обнаружить как в контексте эстетики, семантики, юриспруденции, так и в технологиях. Соответ-

ственно, цель данной работы - прояснение статуса репродукции и ее функций в современном социокультурном пространстве.

Если в технической сфере китайское всеобъемлющее копирование, очевидно, становится угрозой интеллектуальной собственности, приводит к миллиардным ущербам и ак- 